\title{
Acute fatty liver of pregnancy and it's anesthetic implications
}

\author{
Haramritpal Kaur', Aarushi Jain², Rupinder Kaur³, Chandni Maheshwari ${ }^{4}$ \\ From ${ }^{1}$ Associate Professor, ${ }^{2}$ Senior Resident, ${ }^{3}$ Junior Resident, ${ }^{4}$ Assistant Professor, Department of Anaesthesia, GGS Medical College and Hospital, \\ Faridkot, Punjab, India
}

\begin{abstract}
Acute fatty liver of pregnancy (AFLP) is a rare and potentially fatal disorder that usually manifests in the third trimester or even sometimes after delivery. Anesthesiologists are an important part of the multidisciplinary team involved in the management of such patients during their perioperative care and as well as in the intensive care unit (ICU). AFLP usually manifests with deranged liver and renal function tests and episodes of hypoglycemia. The diagnosis is typically clinical. Prompt delivery and supportive care in ICU are the cornerstone of treatment. We, hereby, describe the successful management of the patient with postpartum AFLP in ICU.
\end{abstract}

Key words: Acute fatty liver, Hypoglycemia, Intensive care unit, Pregnancy

A cute fatty liver of pregnancy (AFLP) is a rare and potentially fatal disorder with an incidence of 1-3 cases per 10,000 pregnancies [1]. AFLP is an obstetric emergency that usually develops in the third trimester of pregnancy or early postpartum period. It is characterized by acute hepatic failure secondary to fatty infiltration of the liver. The spectrum of disease can range from mild symptoms to gross derangements.

This case report describes the successful management of a pregnant female who developed AFLP in the postpartum period and was managed in the intensive care unit (ICU). This case highlights the importance of vigilant monitoring that can help detect this fatal disease, and hence, early intervention can save precious lives.

\section{CASE REPORT}

A 22-year-old full-term primigravida presented to the emergency with complaints of altered sensorium and an episode of seizure in the morning. The patient had a history of mild abdominal pain, nausea, and headache for 2 days. There was no other significant medical, surgical, or obstetric history.

On admission, her vitals were blood pressure (BP) $180 / 120 \mathrm{~mm}$ of $\mathrm{Hg}$, heart rate $-88 / \mathrm{min}$, and saturation of arterial blood (SPO2) of 94\%. She was afebrile. There was no jaundice or icterus at presentation. Fetal heart sounds were present.

Ultrasonography (USG) showed a single viable fetus. Laboratory investigations showed deranged liver function tests

\section{Access this article online}

Received - 08 September 2020

Initial Review - 24 September 2020

Accepted - 28 September 2020

DOI: 10.32677/IJCR.2020.v06.i10.005
(LFTs), deranged renal functional tests (RFTs), and leukocytosis (Table 1). There were traces of proteins in the urine. The patient was irritable.

The emergency lower section caesarian section (LSCS) was done under general anesthesia (GA) with a presumptive diagnosis of eclampsia. The intraoperative period was uneventful. A live female child was born with an APGAR score of 3 and was shifted immediately to the neonatal ICU in an intubated state. The patient was shifted to ICU in an intubated state in view of preoperative altered mental status, deranged LFTs, poor respiratory efforts, and arterial blood gas analysis showing $\mathrm{pH} 7.288$, partial pressure of carbon dioxide (pCO2) $18.2 \mathrm{~mm} \mathrm{Hg}$, partial pressure of oxygen (pO2) $208.3 \mathrm{~mm} \mathrm{Hg}$, bicarbonate $8.7 \mathrm{meq} / \mathrm{L}$, and base excess $15.8 \mathrm{meq} / \mathrm{L}$.

On ICU arrival, her vitals were BP 150/100, pulse rate $98 / \mathrm{min}$, and $\mathrm{SpO} 2100 \%$ on a ventilator. Her vitals remained stable during her stay in ICU without any inotropic support. Mechanical ventilation was initiated on synchronized intermitted mandatory ventilation mode with tidal volume - $350 \mathrm{ml}$, FiO2 - 40\%, pressure support 12, and positive end-expiratory pressure of 5 . Sedation and analgesia were ensured with midazolam and fentanyl infusions. Medicine and neurology consultations were taken.

Computer tomography of the head and magnetic resonance imaging of the brain was done to rule out any intracranial bleed. Repeat USG abdomen showed normal-sized liver with raised echotexture suggesting fatty infiltration (Fig. 1). Her LFTs and RFTs deteriorated further during her stay in ICU post-LSCS (Table 1). Urine output also started decreasing. The coagulation profile also showed derangement (Table 1), for which 4 units of fresh frozen plasma (FFP) were transfused.

Correspondence to: Dr. Haramritpal Kaur, Department of Anaesthesia, GGS Medical College and Hospital, Faridkot, Punjab, India. E-mail: amritk_dr@ggsmch.org

(C) 2020 The Author(s). This open access article is distributed under a Creative Commons Attribution (CC-BY) 4.0 license. 
Table 1: Sequential investigations of the patient

\begin{tabular}{|c|c|c|c|c|}
\hline Parameters & Before delivery & ICU day 1 & ICU day 2 & ICU day 4 \\
\hline Hemoglobin (g/dl) & 11.5 & 9.8 & 10.2 & 10.1 \\
\hline Total leukocyte count (cells/ml3) & 15,300 & 13,800 & 12,100 & 10,500 \\
\hline Platelets (cells/ $\mu \mathrm{l})$ & 151,000 & 208,000 & 210,000 & 215,000 \\
\hline Blood urea (mg/dl) & 103 & 123 & 122 & 94 \\
\hline Serum creatinine $(\mathrm{mg} / \mathrm{dl})$ & 4.3 & 4.3 & 5 & 1 \\
\hline Total/direct bilirubin (mg/dl) & $0.8 / 0.3$ & $1.0 / 0.5$ & $0.4 / 0.1$ & $0.4 / 0.1$ \\
\hline Aspartate aminotransferase (IU/L) & 241 & 372 & 377 & 80 \\
\hline Alanine aminotransferase (IU/L) & 171 & 301 & 384 & 98 \\
\hline Alkaline phosphatase (IU/L) & 450 & 453 & 448 & 297 \\
\hline Prothrombin time/INR & $86.6 / 1.17$ & $80 / 1.5$ & $70 / 1.7$ & $92.8 / 1.08$ \\
\hline Viral markers & \multicolumn{4}{|c|}{ Non-reactive } \\
\hline
\end{tabular}

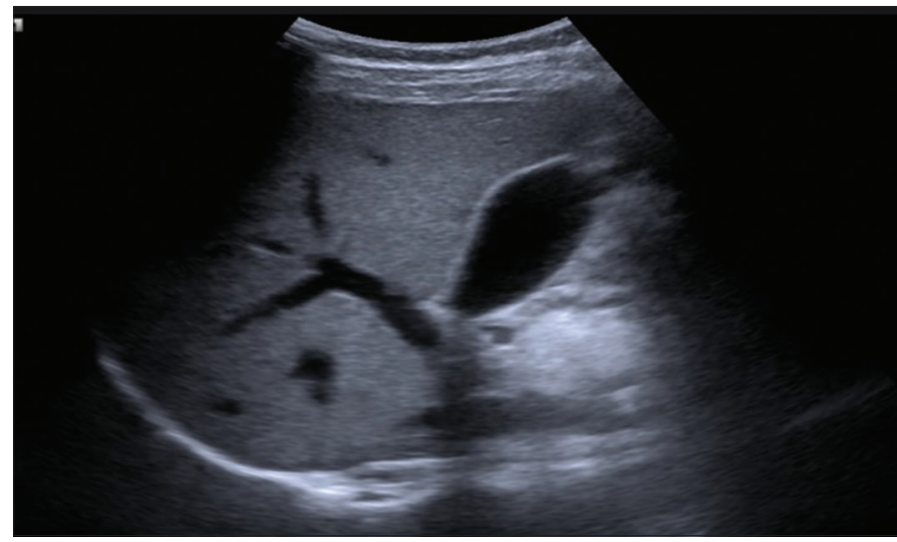

Figure 1: Ultrasonogram showing raised echotexture of the liver

In ICU on the $2^{\text {nd }}$ post-operative day, the patient had frequent episodes of decreased consciousness/stare look which correlated well with hypoglycemia (blood glucose $40 \mathrm{mg} / \mathrm{dl}$ or below) and which responded to dextrose infusions. The patient was treated with a $25 \%$ Dextrose infusion, followed by continuous dextrose $10 \%$ infusion with RBS monitoring.

The patient gradually improved with supportive care in the ICU, including broad-spectrum antibiotics, fluid support, mechanical ventilation, and correction of complications like hypoglycemia. The patient was gradually weaned off from the mechanical ventilation within $48 \mathrm{~h}$, postoperatively. The LFTs and RFTs started improving from day 4 in ICU and the patient was shifted from ICU to ward after 8 days in hemodynamically stable condition.

\section{DISCUSSION}

AFLP was first described in 1934 by Stadder and Cadden as acute yellow atrophy of the liver. It was thought to be a variant of preeclampsia. With the advancement in diagnostic techniques, early reorganization and differential from other liver disorders of pregnancy are now possible. More advanced multidisciplinary care has now resulted in the maternal mortality rate to be $7-18 \%$ and the fetal mortality rate 9-23\% [2]. AFLP usually presents between the $30^{\text {th }}$ and $38^{\text {th }}$ weeks of gestation. However, there are a few reported cases of AFLP in the second trimester [3].
The precise pathogenesis of AFLP is not clear, a proposed hypothesis is an accumulation of free fatty acids in the liver due to inadequate activity of mitochondrial long-chain 3-hydroxyacetyl CoA dehydrogenase [4]. Another theory of fetal fatty acid oxidation disorders is also linked with the pathogenesis of AFLP [1]. Scott Rector et al. have first to report the association between recurrent maternal AFLP with a fetal fatty acid oxidation disorder in two siblings who both died at 6 months of age [5].

Maternal hepatotoxicity and mitochondrial dysfunction occur secondary to the accumulation of hepatotoxic long-chain fatty acid metabolites which had crossed the placental barrier and have reached the maternal side of the circulation. High levels of free fatty acids increase the reactive oxygen species, caspase activity, and hence induce apoptosis [6]. Another common finding in these patients is fatty infiltration of other organs as well. It is more common in females with multiple pregnancies and lower body mass index.

It usually presents as non-specific symptoms of nausea, malaise, vomiting, headache, epigastric pain, and jaundice, leading to rapidly developing severe liver dysfunction, disseminated intravascular coagulation, hypoglycemia, and hepatic encephalopathy. Due to its variable presentation, diagnosis is usually delayed or missed or confused with other hepatic disorders of pregnancy (Table 2) [2]. Other hepatic disorders that need to be considered include are not limited to obstetric cholestasis, HELLP syndrome, preeclamptic liver dysfunction, and hyperemesis gravidarum with liver dysfunction (Table 2).

AFLP is typically a clinical diagnosis made on the basis of SWANSEA criteria (Table 3). Confirmatory diagnosis is by liver biopsy which shows swollen pale hepatocytes and intrahepatic fat lobules. However, the liver biopsy is rarely performed due to risks associated with the procedure [1].

Management of AFLP is usually supportive and similar to that of hepatic failure from other causes. A recent UK-wide Obstetric Surveillance System study also suggests that management is now improving, with $60 \%$ of women with AFLP are admitted in ICU, and mortality is $<2 \%$ or 5 cases/ 1 lac in their case series of 57 patients [7]. Prompt delivery is recommended to avoid maternal deterioration and intrauterine death. Supportive care, including fluid management, maintenance of glucose levels, and correction 
Table 2: Different hepatic disorders of pregnancy [2]

\begin{tabular}{llll}
\hline HELLP syndrome & Obstetric cholestasis & Preeclamptic liver dysfunction & $\begin{array}{l}\text { Hyperemesis gravidarum with } \\
\text { liver dysfunction }\end{array}$ \\
\hline $\begin{array}{l}\text { Elevated aspartate aminotransferase } \\
\text { level }(>70 \mathrm{U} / \mathrm{L})\end{array}$ & $\begin{array}{l}\text { Pruritus } \\
\text { Elevated transaminase and/or }\end{array}$ & $\begin{array}{l}\text { Elevated liver enzyme or } \\
\text { bilirubin level }\end{array}$ & $\begin{array}{l}\text { Elevated liver enzyme or } \\
\text { bilirubin level }\end{array}$ \\
$\begin{array}{ll}\text { Hemolysis }(\text { lactate dehydrogenase level } \\
>600 \mathrm{U} / \mathrm{L})\end{array}$ & $\begin{array}{l}\text { bile acid levels in the second or } \\
\text { third trimester }\end{array}$ & $\begin{array}{l}\text { Hypertension } \\
\text { Proteinuria, after 20 weeks of } \\
\text { gestation }\end{array}$ & $\begin{array}{l}\text { Persistent vomiting, }>1 \text { week } \\
\text { during first or second trimester }\end{array}$ \\
\hline
\end{tabular}

Table 3: SWANSEA criteria for the diagnosis of acute fatty liver of pregnancy, six or more of the following findings are required in the absence of another cause

\begin{tabular}{l}
\hline 1. Vomiting \\
2. Abdominal pain \\
3. Polydipsia/polyuria \\
4. Encephalopathy \\
5. Elevated bilirubin $>14 \mu \mathrm{mol} / 1$ \\
6. Hypoglycemia $<4 \mathrm{mmol} / 1$ \\
7. Elevated uric acid $>340 \mu \mathrm{mol} / 1$ \\
8. Leukocytosis $>11 \times 10^{9} / \mathrm{L}$ \\
9. Ascites or bright liver on ultrasound scan \\
10. Elevated transaminases $(\mathrm{AAT}$ or ALT) $>42 \mathrm{IU} / 1$ \\
11. Elevated ammonia $>47 \mu \mathrm{mol} / 1$ \\
12. Renal impairment: Creatinine $>150 \mu \mathrm{mol} / 1$ \\
13. Coagulopathy: Prothrombin time $>14 \mathrm{~s}$ or APPT $>34 \mathrm{~s}$ \\
14. Microvesicular steatosis on liver biopsy \\
\hline
\end{tabular}

of coagulopathy, is required. Sepsis usually occurs in $50 \%$ of patients and is a major cause of morbidity and mortality. Hence, prophylactic antibiotics are needed. Vitamin K and FFP may be needed if coagulopathy ensues. AFLP is usually self-limiting, but rarely liver transplantation may be needed if a fulminant hepatic failure occurs. Future pregnancies should be discussed, including uncertain recurrence risk as few reoccurrences have been reported in the literature [8]. In severe form, it can be fatal. Ziki et al. reported a case of 18-year-old primigravida who developed AFLP. Despite the best possible efforts, she deceased in the third postpartum day [9]. In some cases, it was preceded by intrahepatic cholestasis of pregnancy. English and Rao reported a case of a 33-year-old woman who presented with pruritus at 34 weeks gestation. A diagnosis of intrahepatic cholestasis of pregnancy was made based on elevated bile acids and elevated liver transaminases. However, postnatally, she developed AFLP [10].

The use of regional anesthesia for labor and cesarean is often debated due to the risk of a rapid deterioration of coagulopathy and the potential risk of a spinal or epidural hematoma. GA poses risks due to hepatic dysfunction, worsening intracranial pressures, and higher risk associated with airway management. Volume replacements and electrolyte imbalances are to be corrected preoperatively. Blood products are kept ready as per hematological investigations. Coadministrations of adjuncts like tranexamic acid can be needed. Careful and close monitoring of hemodynamics is mandatory with judicious use of central line, arterial lines, and vasopressors, or even cerebral vasodilators if needed. A decision needs to be individualized depending on the presenting symptoms, investigations available, and in consultation with the obstetric team.

\section{CONCLUSION}

AFLP is an underdiagnosed disease and should be kept in the differential diagnosis of pregnant females with deranged liver and renal function tests, especially with episodes of hypoglycemia. Early detection with advancements in critical care management has changed AFLP from being a highly fatal complication to a treatable entity.

\section{REFERENCES}

1. Naoum EE, Leffert LR, Chitilian HV, Gray KJ, Bateman BT. Acute fatty liver of pregnancy: Pathophysiology, anesthetic implications, and obstetrical management. Anesthesiology 2019;130:446-61.

2. Westbrook RH, Dusheiko G, Williamson C. Pregnancy and liver disease. J Hepatol 2016;64:933-45.

3. Monga M, Katz R. Acute fatty liver in the second trimester. Obstet Gynecol 1999;93:811-3.

4. Spence D. Case report: Anesthetic management of acute fatty liver of pregnancy in the postpartum period. AANA J 2010;78:223-8.

5. Rinaldo P, Raymond K, Al-Odaib A, Bennett MJ. Clinical and biochemical features of fatty acid oxidation disorders. Curr Opin Pediatr 1998;10:615-21.

6. Natarajan SK, Thangaraj KR, Eapen CE, Ramachandran A, Mukhopadhya A, Mathai M, et al. Liver injury in acute fatty liver of pregnancy: Possible link to placental mitochondrial dysfunction and oxidative stress. Hepatology 2010;51:191-200.

7. Griffiths S, Nicholson C. Anaesthetic implications for liver disease in pregnancy. BJA Educ 2015;16:21-5.

8. Usta IM, Barton JR, Amon EA, Gonzalez A, Sibai BM. Acute fatty liver of pregnancy: An experience in the diagonosis and management of fourteen cases. Am J Obstet Gynecol 1994;171:1342-8.

9. Ziki E, Bopoto S, Madziyire MG, Madziwa D. Acute fatty liver of pregnancy: A case report. BMC Pregnancy Childbirth 2019;19:259.

10. English N, Rao J. Acute fatty liver of pregnancy with hypoglycaemia, diabetes insipidus and pancreatitis, preceded by intrahepatic cholestasis of pregnancy. BMJ Case Rep 2015;15:bcr2015209649.

Funding: None; Conflicts of Interest: None Stated.

How to cite this article: Kaur H, Jain A, Kaur R, Maheshwari C. Acute fatty liver of pregnancy and it's anesthetic implications. Indian J Case Reports. 2020;6(10):560-562. 